\title{
I157172, a novel inhibitor of cystathionine $\gamma$-lyase, inhibits growth and migration of breast cancer cells via SIRT1-mediated deacetylation of STAT3
}

\author{
LUPENG WANG $^{1 *}$, HAIMEI SHI $^{2 *}$, XIAOYU ZHANG ${ }^{1 *}$, XIULI ZHANG $^{3}$, YA LIU $^{1}$, \\ WENYI KANG $^{1,4}$, XIAOYAN SHI ${ }^{1}$ and TIANXIAO WANG ${ }^{1,4}$ \\ ${ }^{1}$ School of Pharmacy, Henan University, Kaifeng, Henan 475004; ${ }^{2}$ Anesthesiology Department, \\ The First Affiliated Hospital, Zhengzhou University, Zhengzhou, Henan 450052; ${ }^{3}$ Department of Botany, \\ Liaoning Agricultural College, Yingkou, Liaoning 115009; ${ }^{4}$ Joint International Research Laboratory \\ of Food \& Medicine, Henan University, Kaifeng, Henan 475004, P.R. China
}

Received June 1, 2018; Accepted October 10, 2018

DOI: $10.3892 /$ or.2018.6798

\begin{abstract}
Cystathionine $\gamma$-lyase (CSE) is highly expressed in breast cancer, and can promote breast cancer development and progression; therefore, inhibitors of CSE may be of great significance for the treatment of breast cancer. The present study identified the CSE inhibitor I157172 through virtual screening and confirmed its activity. Subsequently, the effects and mechanism of 1157172 on breast cancer cells were investigated. MTS and 5-ethynyl-2'-deoxyuridine (EdU) assays were used to assess cell viability and proliferation. Scratch wound and Transwell assays were conducted to determine cell migration and invasion. In addition, $\mathrm{H}_{2} \mathrm{~S}$ determination was performed using the methylene blue method, and western blotting was performed to detect protein expression. The results revealed that 157172 significantly inhibited the growth, proliferation and migration of MCF7 breast cancer cells in a dose-dependent manner. The results of further mechanistic studies demonstrated that CSE expression was negatively associated with sirtuin 1 (SIRT1) in human breast cancer tissues and cells, and CSE knockdown resulted in an increase in SIRT1 expression, and a decrease in acetylated (acetyl)signal transducer and activator of transcription 3 (STAT3) and phosphorylated (p)-STAT3 levels in MCF7 cells. Furthermore, STAT3 downstream proteins B-cell lymphoma 2, p-protein
\end{abstract}

Correspondence to: Professor Tianxiao Wang or Professor Xiaoyan Shi, School of Pharmacy, Henan University, 1 Jinming Avenue, Kaifeng, Henan 475004, P.R. China

E-mail: wtx1975@126.com

E-mail: shisheep@126.com

${ }^{*}$ Contributed equally

Key words: cystathionine $\gamma$-lyase, sirtuin 1, deacetylation, signal transducer and activator of transcription 3, cystathionine $\gamma$-lyase inhibitor kinase B, matrix metalloproteinase (MMP)-2 and MMP-9 were inhibited in CSE knockdown MCF7 cells. In addition, I157172 induced upregulation of SIRT1, and downregulation of acetyl-STAT3 and p-STAT3 (Tyr705), as well as inhibition of STAT3 downstream proteins. Taken together, I157172 inhibited the growth, proliferation and migration of breast cancer cells via upregulating SIRT1, which consequently mediated deacetylation of STAT3 and inactivation of the STAT3 pathway.

\section{Introduction}

Breast cancer is the most frequent type of cancer in women worldwide, and the leading cause of cancer-associated mortality in women in China (1). The identification of novel biomarkers involved in breast cancer progression may provide potential approaches for diagnosis and treatment.

Hydrogen sulfide $\left(\mathrm{H}_{2} \mathrm{~S}\right)$ is the third gasotransmitter signaling molecule, alongside nitric oxide and carbon monoxide, which serves important roles in several physiological processes (2-7). Furthermore, $\mathrm{H}_{2} \mathrm{~S}$ is able to induce cancer cell proliferation (8). Cystathionine $\gamma$-lyase (CSE) is an endogenous $\mathrm{H}_{2} \mathrm{~S}$-producing enzyme. A previous study revealed that endogenous $\mathrm{H}_{2} \mathrm{~S}$ produced by CSE promotes proliferation of human hepatoma cells (9). Furthermore, our previous study indicated that CSE is overexpressed in breast cancer and demonstrated the biological functions of the $\mathrm{CSE} / \mathrm{H}_{2} \mathrm{~S}$ system in promoting breast cancer development and progression (10); therefore, CSE may be considered a novel target and marker involved in the progression of breast cancer. The study of CSE inhibitors may be of great significance for the treatment of breast cancer.

Signal transducer and activator of transcription 3 (STAT3), which is a transcription factor that regulates critical cell functions, is constitutively activated in various human cancer cells and has significant roles in cancer cell growth via the regulation of gene expression (11-15). Our previous study revealed that high expression levels of CSE promote the activation of STAT3 (10); however, it remains unclear as to how CSE activates STAT3. 
The acetylation of STAT3 is crucial for its activation and stabilization of its dimer (16-20). Sirtuin 1 (SIRT1) is a histone deacetylase dependent on $\mathrm{NAD}^{+}$, and SIRT1-induced deacetylation of STAT3 serves a role in numerous physiological processes $(21,22)$. Numerous studies have confirmed that SIRT1 has an important role in breast cancer (23-25). However, a novel finding suggested that SIRT1 serves a dual role in breast tumors, depending on its expression rate and the molecular subtype of the cancer (26). The aim of the present study was to determine the expression levels of SIRT1 in breast cancer tissues and cells with high CSE expression, and to investigate whether the $\mathrm{CSE} / \mathrm{H}_{2} \mathrm{~S}$ system is involved in STAT3 activation via SIRT1 in breast cancer.

The present study used virtual screening to identify inhibitors of CSE, and confirmed the inhibitory function of I157172 on CSE and the anticancer effects of the CSE inhibitor 1157172 in breast cancer. This study also investigated whether inhibition of the $\mathrm{CSE} / \mathrm{H}_{2} \mathrm{~S}$ system may mediate inactivation of STAT3 via SIRT1. Furthermore, the effects of I157172 on SIRT1/acetylated (acetyl)-STAT3 were detected to confirm the downstream pathway of the $\mathrm{CSE} / \mathrm{H}_{2} \mathrm{~S}$ system. The present study may provide a novel target for the treatment of breast cancer, and CSE inhibitors may be considered potential candidates for the treatment of breast cancer.

\section{Materials and methods}

Virtual screening of CSE inhibitors. Initially, the crystal structure of CSE protein [Protein Data Bank (PDB) ID: 3COG] was downloaded from the PDB (http://www. rcsb.org/pdb). The binding pocket was identified by the Site Finder module with empirical confirmation. The target library (the SPECS compound library) was prepared with the Wash module in Molecular Operating Environment (MOE) 2014.09 (Chemical Computing Group ULC, Montreal, QC, Canada). High throughput rigid docking, followed by flexible docking with force field refinement, was used to rank the compounds, in order to achieve a balance between accuracy and efficiency.

MOE Dock was used for docking simulations of the ligands and predicting their binding affinity with the homology model. The 2D structures of the ligands were drawn in ChemOffice (2013; PerkinElmer, Inc., Waltham, MA, USA) and converted to $3 \mathrm{D}$ in MOE through energy minimization. The flexible docking protocol followed the 'induced fit' protocol, in which the side chains of the receptor pocket were allowed to move according to ligand conformations, with a constraint on their positions. The weight used for tethering side chain atoms to their initial positions was 10. Prior to docking, the force field of AMBER12:EHT and the implicit solvation model of Reaction Field (R-field) were selected. The protonation state of the protein and the orientation of the hydrogens were optimized by LigX, at a pH of 7.0 and temperature of $300 \mathrm{~K}$. For rigid docking, the docked poses of the ligands were ranked by London dG scoring. For flexible docking, a force field refinement was conducted on the top 30 poses followed by rescoring of GBVI/WSA dG. MOE Dock, AMBER12:EHT, R-field and GBVI/WSA dG are programs belonging to the MOE 2014.09 software package.
Compound 1157172 and positive controls. I157172, also known as 2-[(4-(2,5-dimethoxyanilino)-6-\{3-nitroanilino\}1,3,5-triazin-2-yl) sulfanyl]-6-ethoxy-1,3-benzothiazole, was purchased from Specs (Zoetermeer, The Netherlands), L-propargylglycine (PAG) was purchased from Sigma-Aldrich; Merck KGaA (Darmstadt, Germany) and doxorubicin (DOX) was obtained from Beijing Solarbio Science \& Technology Co., Ltd. (Beijing, China). PAG is an existing CSE inhibitor and DOX is a common clinical antitumor drug; therefore, PAG and DOX were used as positive controls.

Patient samples and cell lines. A total of 16 breast cancer tumor samples and adjacent non-tumor samples were collected from patients. All of the patients (age, 37-60 years; no smoking history available) had a non-specific type of invasive breast cancer (4 cases of grade II and 12 cases of grade III breast cancer) and were recruited from the Huaihe Hospital (Kaifeng, China). The present study was approved by the ethics committee of the Medical School, Henan University (Kaifeng, China), and patients provided written informed consent. MCF7 and MDA-MB-231 human breast cancer cell lines, and the Hs578Bst mammary epithelial cell line were obtained from the American Type Culture Collection (Manassas, VA, USA). The cells were cultured in Dulbecco's modified Eagle's medium (Gibco; Thermo Fisher Scientific, Inc., Waltham, MA, USA) supplemented with $10 \%$ fetal bovine serum (FBS; Zeta Life, Inc., San Francisco, CA, USA) at $37^{\circ} \mathrm{C}$ in an atmosphere containing $5 \% \mathrm{CO}_{2}$.

Determination of $\mathrm{H}_{2} \mathrm{~S}$ production. $\mathrm{H}_{2} \mathrm{~S}$ determination was performed using the methylene blue method. Briefly, MCF7 cells $\left(1 \times 10^{6} / \mathrm{ml}\right)$ were seeded into a 6 -well tissue culture plate.

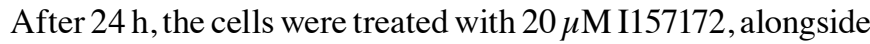
$2 \mathrm{mM}$ L-cysteine and $0.5 \mathrm{mM}$ pyridoxal phosphate for $24 \mathrm{~h}$ at $37^{\circ} \mathrm{C}$. Concurrently, $1 \%(\mathrm{w} / \mathrm{v})$ zinc acetate $(500 \mu \mathrm{l})$ was added to filter papers adhered to the lid of the 6-well tissue culture plate for $24 \mathrm{~h}$, in order to absorb $\mathrm{H}_{2} \mathrm{~S}$. Then the filter papers were placed into tubes containing $0.2 \%(\mathrm{w} / \mathrm{v}) \mathrm{N}, \mathrm{N}$-dimethylp-phenylenediamine-dihydrochloride dye (500 $\mu \mathrm{l}), 10 \%(\mathrm{w} / \mathrm{v})$ ammonium ferric sulfate $(50 \mu \mathrm{l})$ and $3 \mathrm{ml} \mathrm{H}_{2} \mathrm{O}$, and were incubated for $20 \mathrm{~min}$ at room temperature. Absorbance at $670 \mathrm{~nm}$ was subsequently measured. The production of $\mathrm{H}_{2} \mathrm{~S}$ was determined using a standard curve of NaHS (0-1 mM; $\left.\mathrm{R}^{2}=0.9998\right)$ and was presented as $\mathrm{nmol} \cdot \mathrm{min}^{-1}$ per $1 \times 10^{6}$ cells. The assay was conducted in triplicate for three independent experiments.

Cell viability and proliferation assays. MTS and 5-ethynyl2'-deoxyuridine (EdU) assays were used to assess cell viability and proliferation, respectively. MCF7 and Hs578Bst cells were plated into 96 -well plates at a density of $1 \times 10^{6} / \mathrm{ml}$, and were treated with $0,2.5,5,10,20,30$ and $40 \mu \mathrm{M}$ I157172 and 0 , $5,10,20$ and $40 \mu \mathrm{M}$ PAG or DOX for 24 or $48 \mathrm{~h}$ at $37^{\circ} \mathrm{C}$. Cell viability was evaluated by determining the number of cells using the MTS assay (Sigma-Aldrich; Merck KGaA), according to the manufacturer's protocol, and images were captured with an inverted microscope (IX53, Olympus Corporation, Tokyo, Japan). The assay was conducted in triplicate for three independent experiments. PAG and DOX served as positive controls. 
Cell proliferation was assessed using the EdU assay kit (Guangzhou Ribobio Co., Ltd., Guangzhou, China). The results of a pre-experiment revealed that treatment of cells with I157172 for $>24 \mathrm{~h}$ cannot accurately reflect cell proliferation. Therefore, in this study, cells were exposed to 1157172 for $24 \mathrm{~h}$ for the cell proliferation assay. Briefly, MCF7 cells $\left(1 \times 10^{6} / \mathrm{ml}\right)$ were cultured in 96-well plates and were exposed to $0,10,20$ and $30 \mu \mathrm{M} \mathrm{I} 157172$ for $24 \mathrm{~h}$ at $37^{\circ} \mathrm{C}$. Subsequently, cells were incubated with $50 \mu \mathrm{m}$ EdU for $2 \mathrm{~h}$ at room temperature, fixed with $4 \%$ formaldehyde for $30 \mathrm{~min}$ at room temperature, incubated with glycine $(2 \mathrm{mg} / \mathrm{ml})$ for $5 \mathrm{~min}$ and treated with $0.5 \%$ Triton X-100 for $10 \mathrm{~min}$ to permeabilize the cells. After being washed with PBS for $5 \mathrm{~min}$, the cells were incubated with $1 \mathrm{X}$ Apollo $^{\circledR} 567$ (Guangzhou Ribobio Co., Ltd.) for $30 \mathrm{~min}$ and treated twice with $0.5 \%$ Triton X-100. DNA was stained with Hoechst 33342 for $30 \mathrm{~min}$ and visualized with fluorescence microscopy. Five groups of cells in the images were randomly selected.

Cell migration and invasion assays. The scratch wound assay was used to determine cell migration. MCF7 cells were seeded into a 6 -well plate and were scraped with a $10-\mu 1$ pipette tip once they reached $\sim 90 \%$ confluence to generate a wound, and were rinsed twice with PBS. Subsequently, the cells were treated with $0,10,20$ and $30 \mu \mathrm{M}$ I157172 and were cultured in medium containing $5 \% \mathrm{FBS}$ for $24 \mathrm{~h}$ at $37^{\circ} \mathrm{C}$. The distance of wound closure was measured at the beginning of the experiment and after $24 \mathrm{~h}$ using an inverted microscope (IX53; Olympus Corporation). The assay was conducted in triplicate for three independent experiments.

A Transwell assay was conducted to analyze invasion. Briefly, 24-well Transwell chambers (pore size, $8 \mu \mathrm{m}$; Corning Incorporated, Corning, NY, USA) were coated with Matrigel matrix (BD Biosciences, San Joes, CA, USA) for $30 \mathrm{~min}$ at $37^{\circ} \mathrm{C}$. MCF7 cells $\left(5 \times 10^{4}\right)$ suspended in $200 \mu 1$ DMEM with $1 \%$ FBS were seeded into the top chambers, whereas DMEM with $15 \%$ FBS was placed into the bottom chambers. MCF7 cells in the top chambers were treated with $0,10,20$ and $30 \mu \mathrm{M} \mathrm{I} 157172$ for $24 \mathrm{~h}$ at $37^{\circ} \mathrm{C}$, and the cells on the upper surface of the membrane were removed. The invasive cells attaching to the lower surface of membrane were fixed with $4 \%$ polyoxymethylene for $30 \mathrm{~min}$ and were stained with $0.1 \%$ crystal violet for 15-20 $\mathrm{min}$ at room temperature. Images of the stained cells were captured with an inverted microscope (IX53; Olympus Corporation). Subsequently, cells were dissolved in $10 \%$ acetic acid and the $\mathrm{OD}_{570}$ absorbance was measure at $570 \mathrm{~nm}$ using a microplate spectrofluorometer (EnSpire; PerkinElmer, Inc.).

siRNA transfection. MCF7 cells in 6-well plates (30-40\% cell confluence) were transfected with $10 \mathrm{nM}$ scramble siRNA (Sc siRNA), or specific siRNA against human CSE (Invitrogen; Thermo Fisher Scientific, Inc.) at a final concentration of $50 \mathrm{nM}$, using Lipofectamine ${ }^{\circledR} 2000$ (Invitrogen; Thermo Fisher Scientific, Inc.) at $37^{\circ} \mathrm{C}$ for $48 \mathrm{~h}$. The medium was replaced $6 \mathrm{~h}$ post-transfection, and silencing efficiency was determined by western blotting $48 \mathrm{~h}$ post-transfection. The sequences for the CSE-specific siRNA were as follows: Sense, 5'-GGUUUAGCAGCCACUGUAAdTdT-3'; antisense, 5'-UUACAGUGGCUGCUAAACCdTdT-3', which were designed to target the open reading frame region of CSE mRNA. The sequences for the Sc siRNA were as follows: Sense, 5'-GTTCCCTATGCGTGAGAAAdTdT-3'; antisense, 5'-GCTTACAAGGGTCTTCACAdTdT-3'.

Western blot analysis. Proteins were extracted from human breast cancer and paracancerous tissues, human breast cancer cells (MCF7 and MDA-MB-231; MCF7 cells were transfected with CSE siRNA for $48 \mathrm{~h}$ or were treated with 10,20 and $30 \mu \mathrm{M}$ I157172 for $24 \mathrm{~h}$ ) and normal mammary epithelial Hs578Bst cells using radioimmunoprecipitation assay buffer $(50 \mathrm{mM}$ Tris-HCl, pH 8.0; 150 mM sodium chloride; $1.0 \%$ NP-40; $0.5 \%$ sodium deoxycholate; and $0.1 \%$ SDS) supplemented with $10 \mu \mathrm{g} / \mathrm{ml}$ phenylmethylsulfonyl fluoride (Sigma-Aldrich; Merck $\mathrm{KGaA}$ ). The samples were then centrifuged at $12,000 \mathrm{x} \mathrm{g}$ for $10 \mathrm{~min}$, and protein concentration was determined using the bicinchoninic acid protein quantitative kit (Solarbio Science $\&$ Technology Co., Ltd.). Protein samples $(40 \mu \mathrm{g})$ were separated by $10 \%$ SDS-PAGE and were transferred to polyvinylidene difluoride membrane (EMD Millipore, Billerica, MA, USA) at $70 \mathrm{~mA}$ for $2 \mathrm{~h}$ at $4^{\circ} \mathrm{C}$. The membrane was then blocked in $5 \%$ fat-free milk for $2 \mathrm{~h}$ at room temperature, and probed with specific primary antibodies against CSE, SIRT1, STAT3, phosphorylated (p)-STAT3, acetyl-STAT3, B-cell lymphoma 2 (BCL-2), matrix metalloproteinase (MMP)-2, MMP-9, protein kinase B (Akt) and p-Akt at $4^{\circ} \mathrm{C}$ overnight. After incubation with the secondary antibodies for $2 \mathrm{~h}$ at room temperature, the proteins were visualized using an EasyBlot Enhanced Chemiluminescence kit (Sangon Biotech Co., Ltd., Shanghai, China) and were detected using a FluorChem Q Multifluor system (ProteinSimple, San Jose, CA, USA) and semi-quantified using Image $2 x$ (National Institutes of Health, Bethesda, MD, USAs). GAPDH was used as a loading control. Primary antibodies were as follows: CSE mouse monoclonal antibody (1:1,000, cat. no. ab54573; Abcam, Cambridge, UK) SIRT1 mouse monoclonal antibody (1:1,000, cat. no. \#8469), STAT3 mouse monoclonal antibody (1:1,000, cat. no. \#9139), p-STAT3 (Tyr705) rabbit polyclonal antibody (1:1,000, cat. no. \#9131), acetyl-STAT3 rabbit polyclonal antibody $(1: 1,000$, cat. no. \#2523), BCL-2 rabbit monoclonal antibody (1:1,000, cat. no. \#2870), MMP-2 rabbit polyclonal antibody $(1: 1,000$, cat. no. \#4022), MMP-9 rabbit polyclonal antibody (1:1,000, cat. no. \#3852), Akt rabbit monoclonal antibody (1:1,000, cat. no. \#4685) and p-Akt rabbit monoclonal antibody (1:1,000, cat. no. \#4060) (Cell Signaling Technology, Inc., Danvers, MA, USA). GAPDH mouse monoclonal antibody $(1: 1,000$, cat. no. AG019) was obtained from Beyotime Institute of Biotechnology (Shanghai, China). Secondary antibodies were as follows: Horseradish peroxidase-conjugated goat anti-rabbit (1:10,000, cat. no. SA00001-2) and horseradish peroxidaseconjugated goat anti-mouse (1:10,000, cat. no. SA00001-1) (Proteintech Group, Inc., Chicago, IL, USA).

Statistical analysis. Each experiment was repeated at least three times. Statistical analyses were performed using SPSS 17.0 software (SPSS, Inc., Chicago, IL, USA). Data are expressed as the means \pm standard deviation. Differences between multiple groups were analyzed using one-way analysis of variance followed by Bonferroni post hoc test. Differences between two groups were analyzed by Student's 

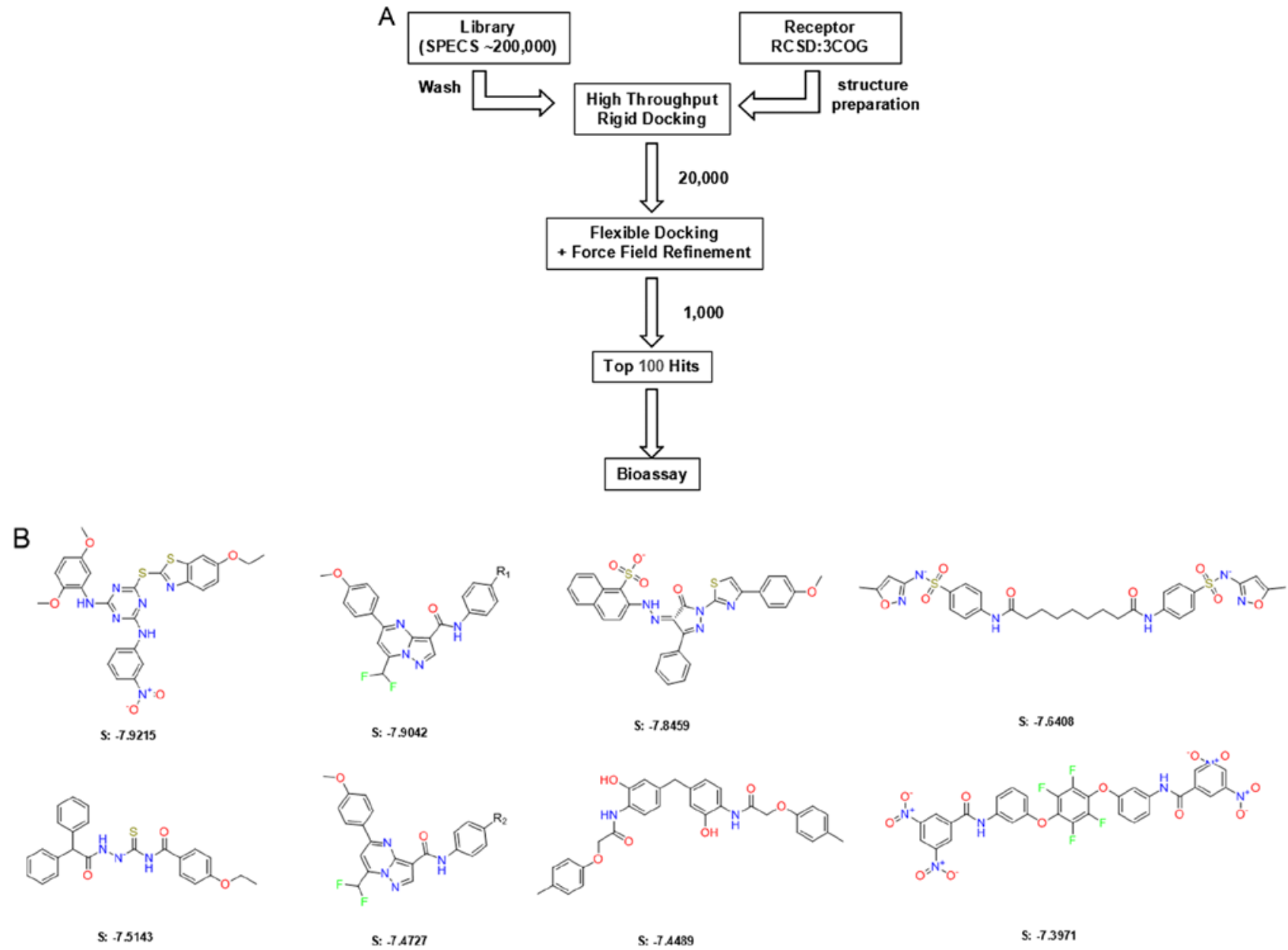<smiles>Cc1ccc(CNC(=O)c2ccc(Cc3ccc(Cc4ccc(OCC(=O)Nc5ccc(O)c(O)c5)cc4)c(O)c3)cc2)cc1</smiles><smiles></smiles><smiles>CCOc1ccc(NC(=O)CCC(=O)NNS(=O)(=O)c2ccc(NC(C)=O)cc2)cc1</smiles>

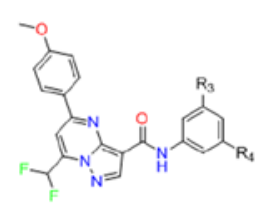<smiles>CCCOC(=O)CCC(=O)NC(=O)NC(=O)c1ccccc1OCC</smiles><smiles>CCCOc1cccc(C(=O)Nc2cc(NC(=O)c3cccc(OCCC)c3)cc(C(=O)O)c2)c1</smiles>

$$
\mathrm{S}:-7.3819
$$$$
\text { S: } 7.3249
$$$$
\text { S: } 7.3219
$$

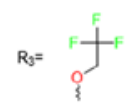

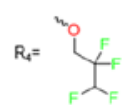

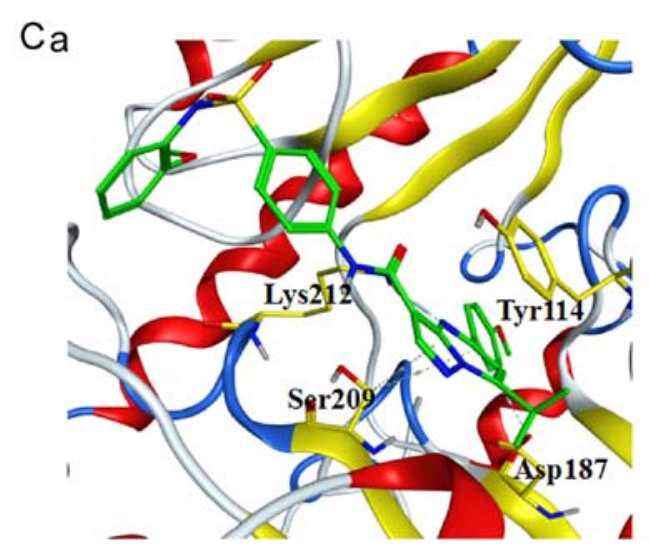

b<smiles>[C+]1[C+]CC1</smiles>

(ㅍ)<smiles>[CH-]</smiles>

(iii)

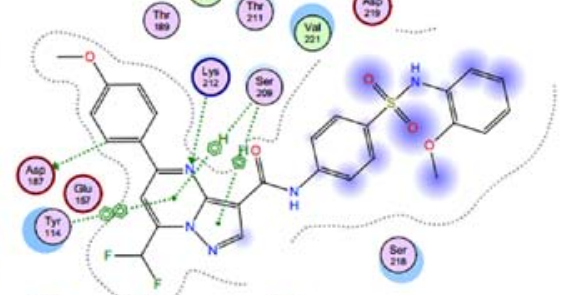

(2)

(iii)

(iiv)

(충

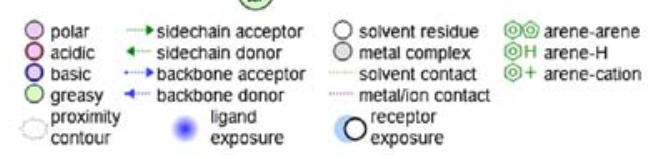

Figure 1. Virtual screening of cystathionine $\gamma$-lyase inhibitors. (A) Virtual screening workflow. (B) Top 12 hits, as identified by virtual screening. $\mathrm{S}$ refers to the binding score, as determined by flexible docking; a lower score suggests a higher affinity. (C) (a) 3D and (b) 2D binding mode of one hit by virtual screening. 
A

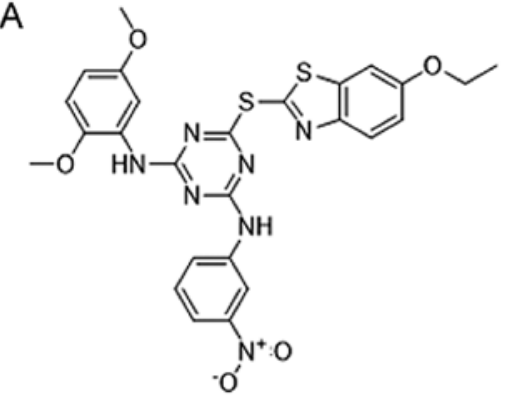

2-\{(4-(2,5-dimethoxyanilino)-6 - $\{3-$ nitroanilino\}-1,3,6triazin-2-yl)sulfanyl]-6-ethoxy-1,3-benzothiazole (1157172)

C

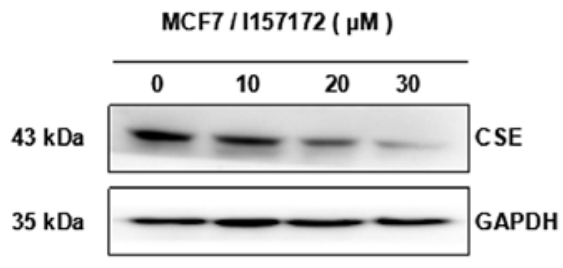

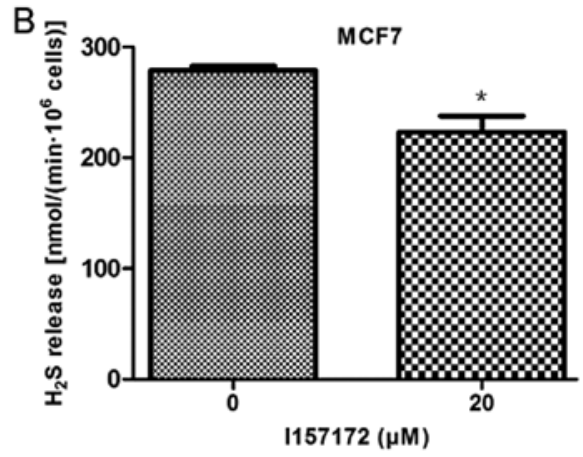

$1157172(\mu \mathrm{M})$

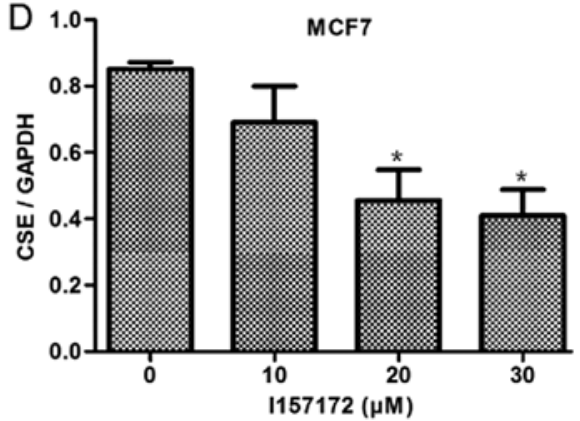

Figure 2. Activity confirmation of the CSE inhibitor I157172. (A) Schematic diagram of I157172. (B) Effects of I157172 on $\mathrm{H}_{2} \mathrm{~S}$ release from MCF7 cells. I157172 inhibited the production of $\mathrm{H}_{2} \mathrm{~S}$ in MCF7 cells. (C and D) Effects of I157172 on the protein expression levels of CSE in MCF7 cells. * $<0.05$ vs. the untreated group. Data are presented as the means \pm standard deviation, obtained from three independent experiments. CSE, cystathionine $\gamma$-lyase; $\mathrm{H}_{2} \mathrm{~S}$, hydrogen sulfide.

t-test. $\mathrm{P}<0.05$ was considered to indicate a statistically significant difference.

\section{Results}

Virtual screening of CSE inhibitors. The flowchart of the virtual screening workflow is depicted in Fig. 1A. MOE Dock was used for docking simulations of the ligands and for predicting their binding affinity with the homology model. The final top 100 hits were selected and the top 12 hits are shown as Fig. 1B. I157172 with the lowest binding score (S:-7.9215) possessed the highest binding affinity with the homology model. The 3D and $2 \mathrm{D}$ binding mode of a compound (S:-7.9042 in Fig. 1B) are predicted and shown in Fig. 1C.

Confirmation of the inhibitory activity of 1157172 on CSE. I157172 was the top hit, as identified by virtual screening, the structure and naming of which are shown in Fig. 2A. To confirm the inhibitory activity of I157172 on CSE, the present study detected the effects of $\mathrm{I} 157172 \mathrm{on}_{2} \mathrm{~S}$ production and CSE protein expression. The results of methylene blue detection indicated that I157172 significantly decreased $\mathrm{H}_{2} \mathrm{~S}$ release from MCF7 cells (Fig. 2B), thus suggesting that I157172 may inhibit the activity of CSE. Western blot analysis revealed that 1157172 markedly inhibited the protein expression levels of CSE in MCF7 cells (Fig. 2C and D). These results confirmed the function of I157172 as a CSE inhibitor.

I157172 inhibits MCF7 cell proliferation, migration and invasion. The results of an MTS assay revealed that 1157172 significantly reduced the viability of MCF7 cells in a dose-dependent manner and the half maximal inhibitory concentration $\left(\mathrm{IC}_{50}\right)$ was $18.51 \mu \mathrm{M}$ after $48 \mathrm{~h}$ (Fig. 3A and $\mathrm{B}$ ). The inhibitory effects of I157172 on MCF7 cells were significantly stronger than those of the CSE inhibitor PAG and were equivalent to those of the positive control DOX at $40 \mu \mathrm{M}$ (Fig. 3C). Furthermore, the damaging effects of 1157172 on Hs578Bst normal mammary cells $\left(\mathrm{IC}_{50}=26.32 \mu \mathrm{M}\right)$ were weaker than those of the positive control DOX $(\mathrm{IC} 50=1.62 \mu \mathrm{M})$ (Fig. 3D). In addition, an EdU assay was performed to further evaluate the inhibitory effects of I157172 on cell proliferation. As shown in Fig. 3E and F, I157172 markedly decreased the number of EdU $\mathrm{MCF}^{+}$cells in a dose-dependent manner. In addition, the inhibitory activities of I157172 on cell migration and invasion were observed in MCF7 cells (Fig. 3G-J). Taken together, the novel CSE inhibitor I157172 may effectively inhibit the proliferation, migration and invasion in MCF7 cells.

$\mathrm{CSE} / \mathrm{H}_{2} \mathrm{~S}$ system may activate STAT3 via the downregulation of SIRT1. Our previous study demonstrated the biological functions of the $\mathrm{CSE} / \mathrm{H}_{2} \mathrm{~S}$ system in promoting breast cancer development and progression, and revealed that upregulation of CSE promotes activation of STAT3 (10). Acetylation of STAT3 is essential for its activation, whereas SIRT1 can induce deacetylation of STAT3 (16-22). To further explore the mechanism underlying the effects of the $\mathrm{CSE} / \mathrm{H}_{2} \mathrm{~S}$ system on the promotion of breast cancer development, this study investigated the effects of the $\mathrm{CSE} / \mathrm{H}_{2} \mathrm{~S}$ system on SIRT1 expression and STAT3 acetylation. The association between CSE and SIRT1 expression in breast cancer tissues and paracancerous tissues was initially investigated. As shown in Fig. 4A and $\mathrm{B}$, SIRT1 expression was reduced in breast cancer tissues 


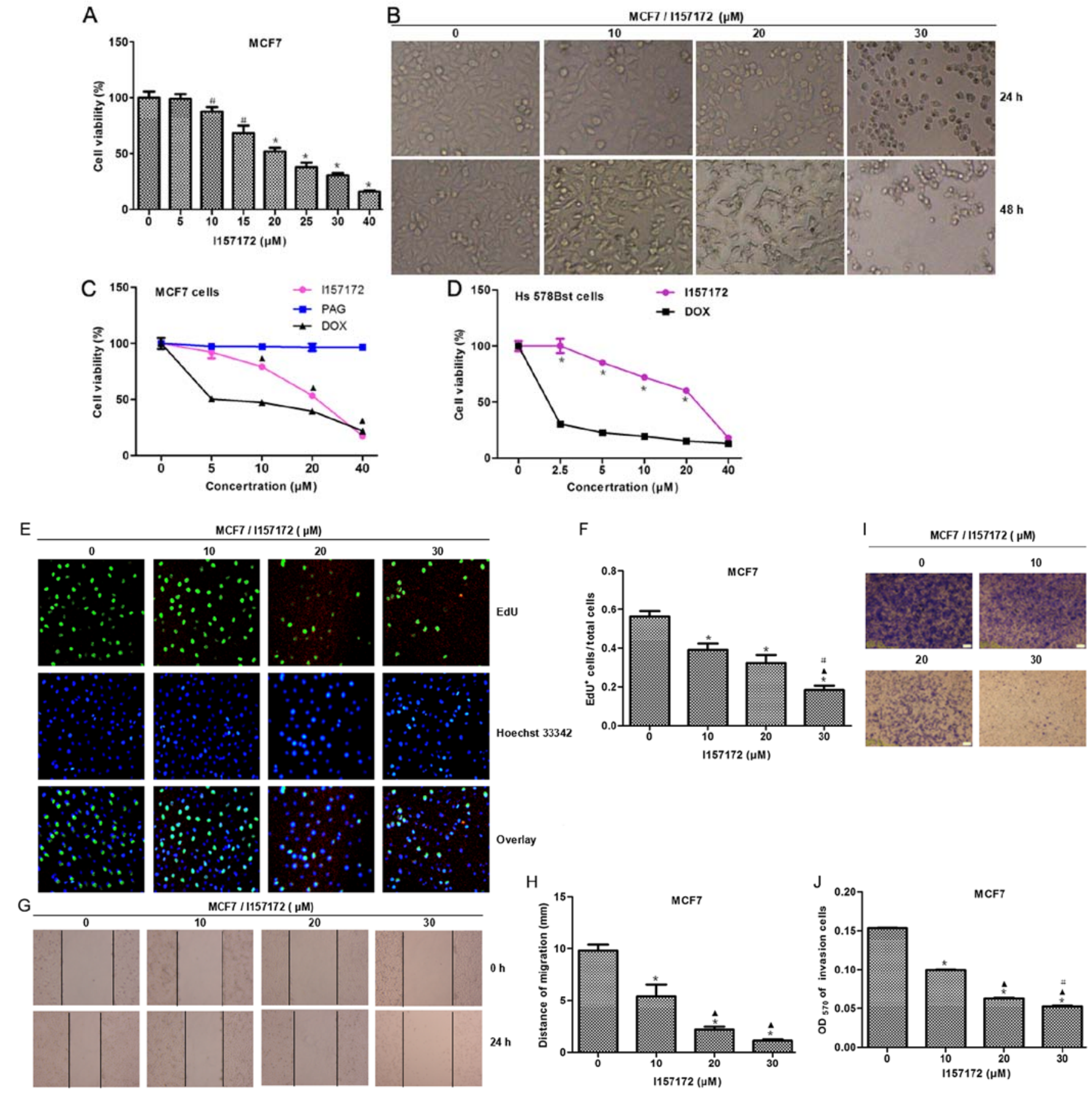

B $\quad$ MCF7/1157172 ( $\mu \mathrm{M})$

Figure 3. Antiproliferative effects of I157172 on breast cancer cells. (A and B) Effects of I157172 on MCF7 cell growth. Cells were exposed to I157172 for 24 and $48 \mathrm{~h}$ prior to the MTS assay. Data are presented as the means \pm standard deviation, obtained from three independent experiments. ${ }^{*} \mathrm{P}<0.05 \mathrm{vs}$. the untreated group, ${ }^{*} \mathrm{P}<0.01$ vs. the untreated group. Image magnification, $\mathrm{x} 400$. (C) Comparison of the antiproliferative activity of I157172 and the positive controls (DOX and the CSE inhibitor PAG) in MCF7 cells. ${ }^{\wedge} \mathrm{P}<0.05$ vs. the PAG group. (D) Comparison of the cytotoxicity of I157172 and the positive control DOX in Hs578Bst normal mammary cells. ${ }^{*} \mathrm{P}<0.05$ vs. the DOX group. (E and F) Effects of $\mathrm{I} 157172$ on cell proliferation, as determined by the EdU assay. $(\mathrm{G}$ and $\mathrm{H})$ Effects of $\mathrm{I} 157172$ on cell migration. (I and J) Effects of I157172 on cell invasion. ${ }^{*} \mathrm{P}<0.05$ vs. the untreated group, ${ }^{\wedge} \mathrm{P}<0.05$ vs. the $10 \mu \mathrm{M}$ I157172 group, ${ }^{"} \mathrm{P}<0.05$ vs. the $20 \mu \mathrm{M} \mathrm{I157172}$ group. Image magnification, x200. CSE, cystathionine $\gamma$-lyase; DOX, doxorubicin; EdU, 5-ethynyl-2'-deoxyuridine; OD, optical density; PAG, L-propargylglycine.

with high CSE expression. Furthermore, low expression levels of SIRT1 were detected in MCF7 and MDA-MB-231 cells, which had high CSE expression levels (Fig. 4C-E). Furthermore, it was revealed that CSE knockdown induced an increase in SIRT1 levels (Fig. 5A-C), and decreased STAT3 (Fig. 5A and D), acetyl-STAT3 (Fig. A and E), and p-STAT3 (Tyr705) levels (Fig. 5A and F) in MCF7 cells. Subsequently, the target proteins downstream of STAT3 were analyzed and it was revealed that knockdown of CSE resulted in downregulation of p-Akt, BCL-2, MMP-2 and MMP-9 proteins (Fig. 5G-L). These data suggested that $\mathrm{CSE} / \mathrm{H}_{2} \mathrm{~S}$ system might promote the activation of STAT3 via reducing the levels of SIRT1.

1157172 promotes SIRT1-mediated deacetylation of STAT3 in breast cancer cells. To further confirm the role of SIRT1 
A
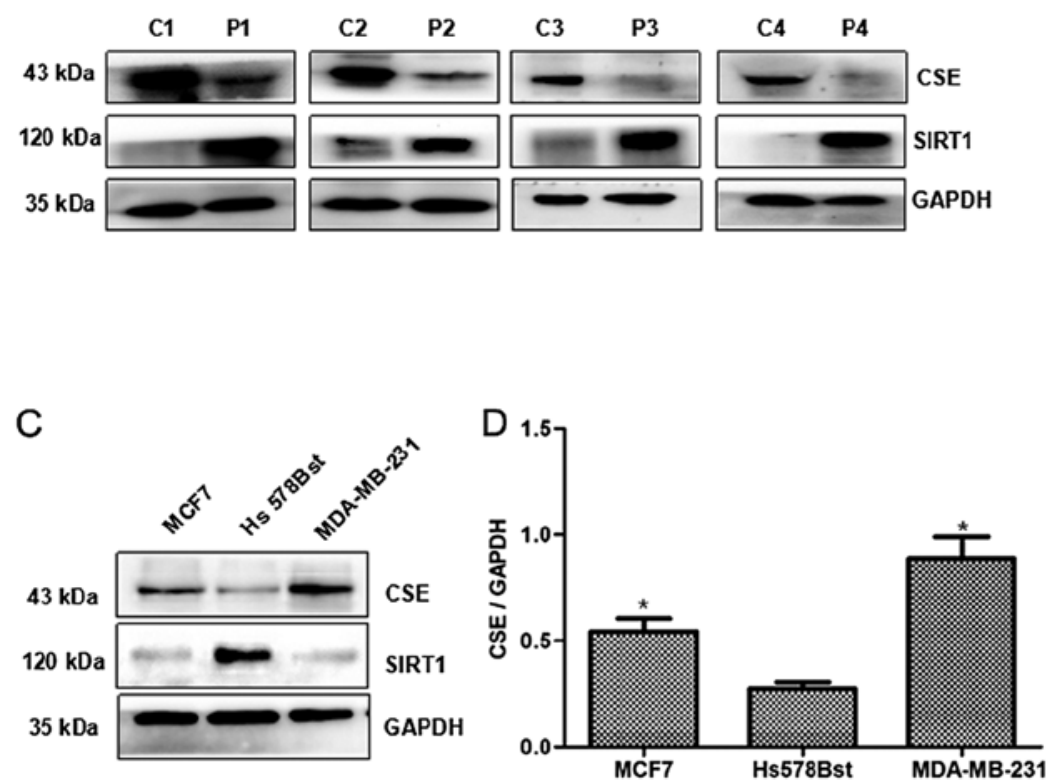
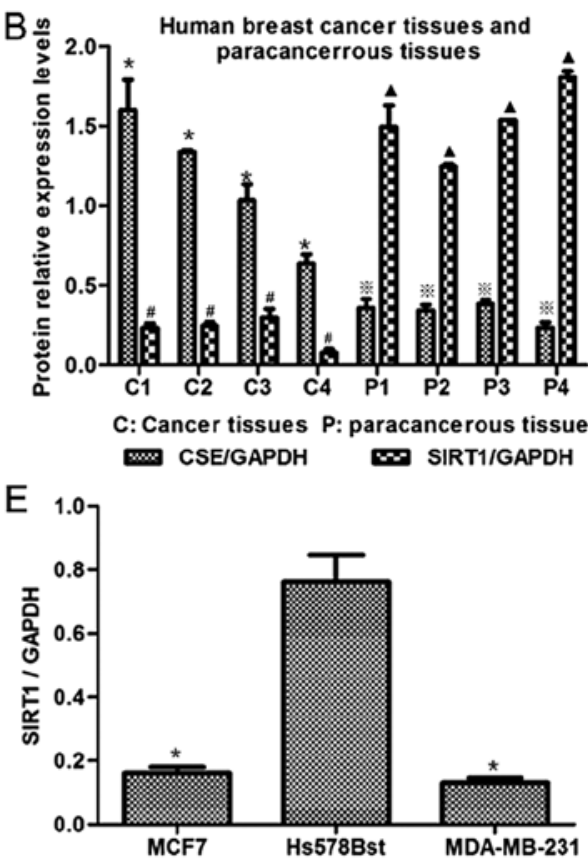

Figure 4. Association between CSE and SIRT1 in breast cancer. (A and B) Expression levels of CSE and SIRT1 in breast cancer tissues and paracancerous tissues. ${ }^{*} \mathrm{P}<0.05$ vs. paracancerous tissues, ${ }^{\wedge} \mathrm{P}<0.05$ vs. cancer tissues, ${ }^{*} \mathrm{P}<0.05$ vs. CSE expression, ${ }^{*} \mathrm{P}<0.05$ vs. SIRT1 expression. (C-E) Expression levels of CSE and SIRT1 in breast cancer cells and normal mammary epithelial cells. "P<0.05 vs. Hs578Bst normal mammary epithelial cells. CSE was highly expressed in breast cancer tissues and cells, and CSE was negatively associated with SIRT1 expression. CSE, cystathionine $\gamma$-lyase; SIRT1, sirtuin 1.

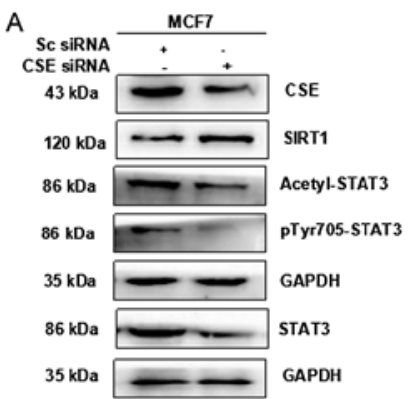

E
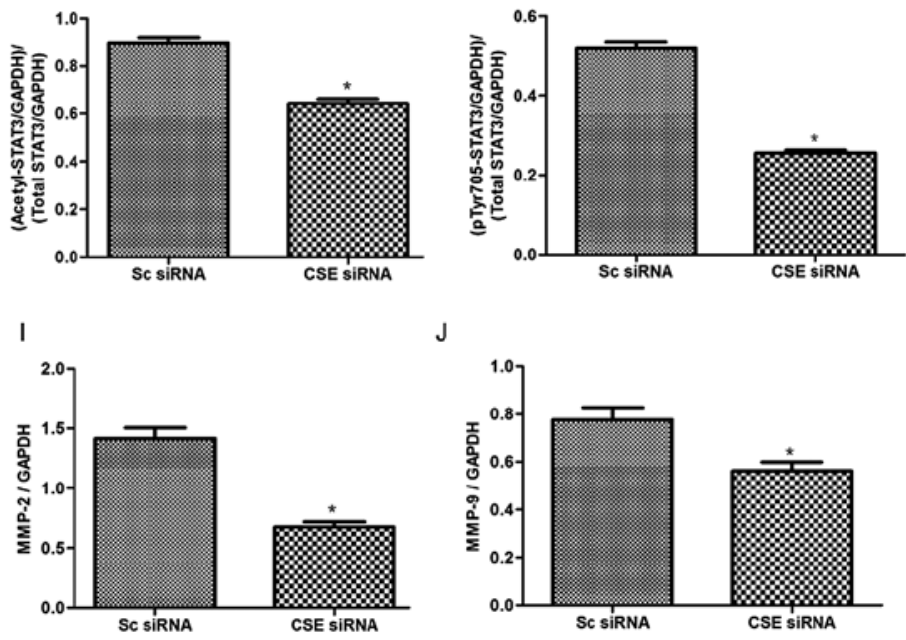

$J$

B

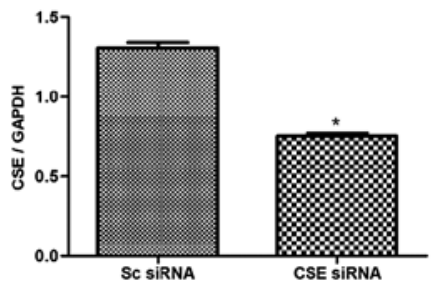

F

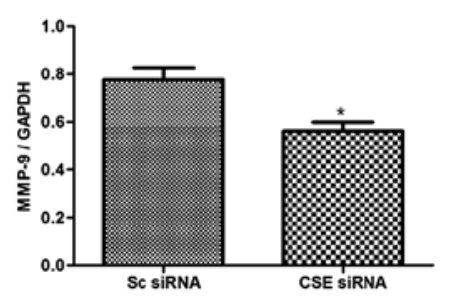

C

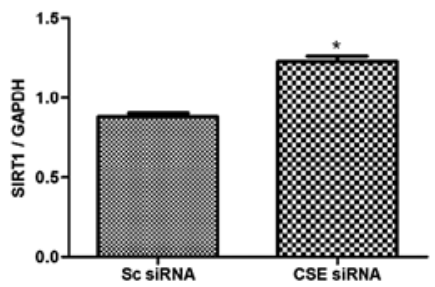

G

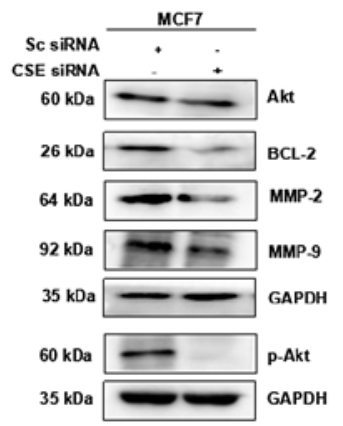

K

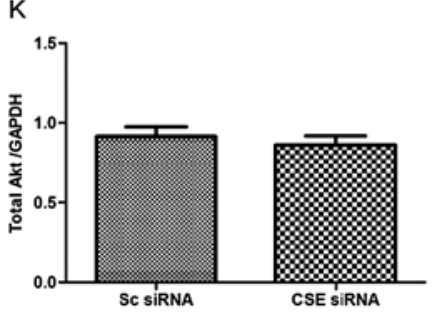

D

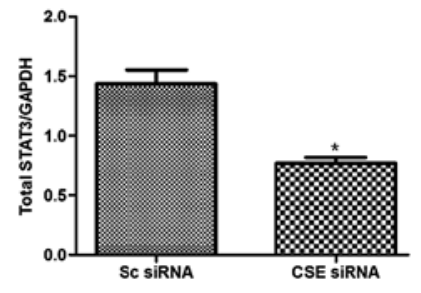

$\mathrm{H}$
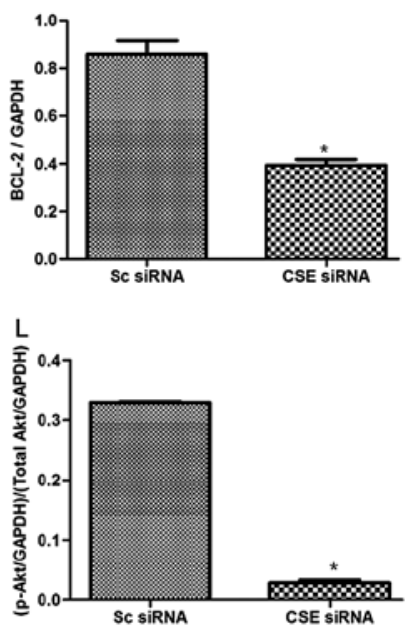

Figure 5. Effects of CSE knockdown on the expression levels of SIRT1 and acetyl-STAT3, and the STAT3 downstream pathway in breast cancer cells. (A-F) Effects of CSE knockdown on SIRT1, acetyl-STAT3 and p-STAT3 expression. CSE knockdown led to an increase in SIRT1 expression, and a decrease in acetyl-STAT3 and p-STAT3. (G-L) Effects of CSE knockdown on STAT3 downstream proteins. CSE siRNA inhibited the expression levels of STAT3 downstream proteins, p-Akt, BCL-2, MMP-2 and MMP-9. 'P<0.05 vs. the Sc siRNA group. Acetyl, acetylated; Akt, protein kinase B; BCL-2, B-cell lymphoma 2; CSE, cystathionine $\gamma$-lyase; MMP, matrix metalloproteinase; p, phosphorylated; Sc, scramble; siRNA, small interfering RNA; SIRT1, sirtuin 1; STAT3, signal transducer and activator of transcription 3. 

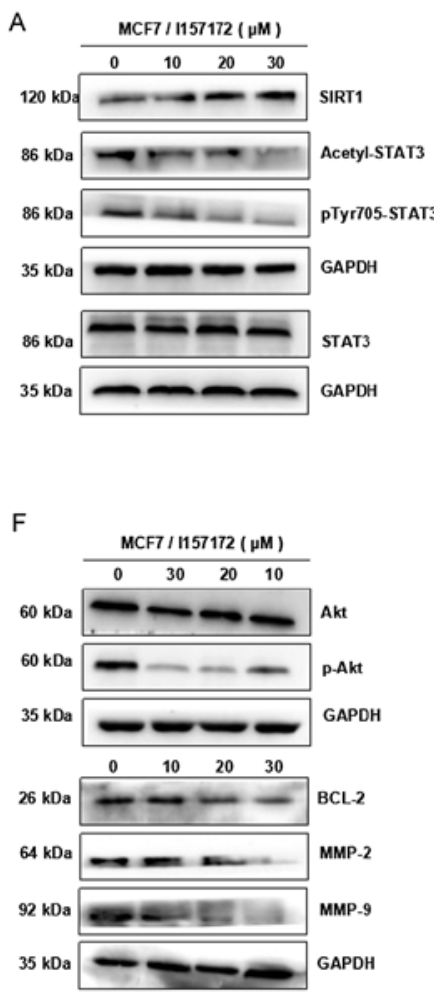
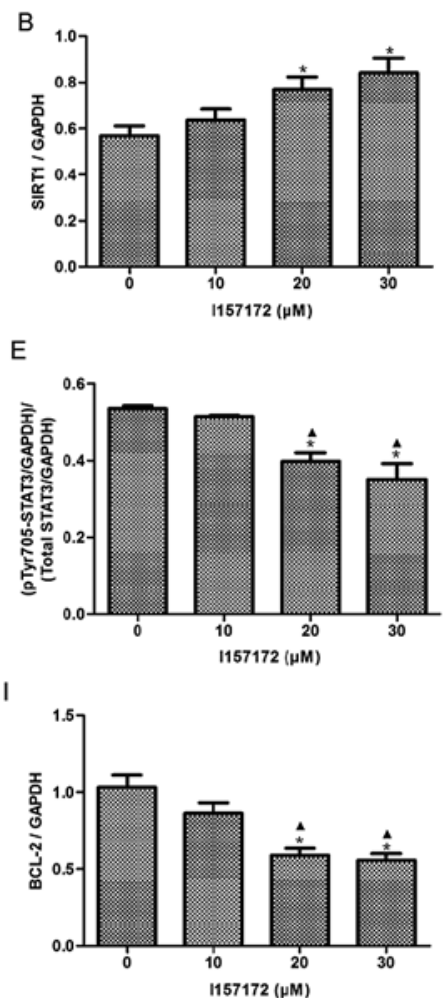
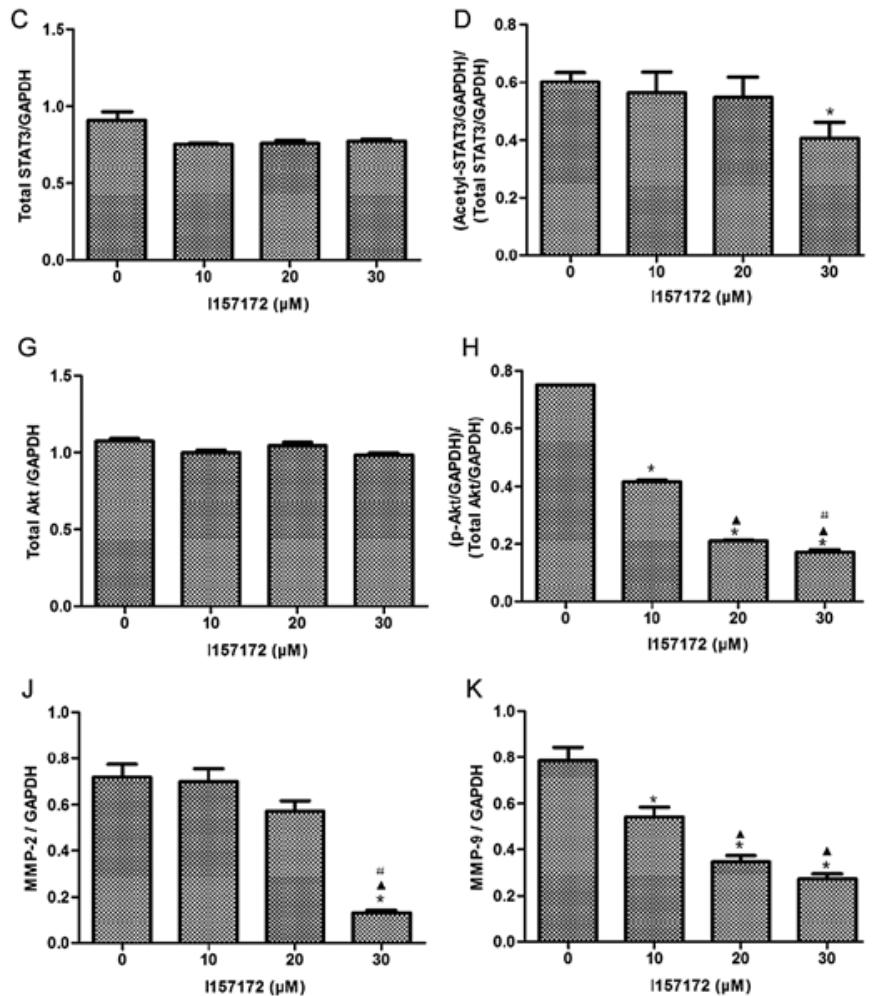

Figure 6. Effects of I157172 on the expression levels of SIRT1 and acetyl-STAT3, as well as STAT3 downstream pathway proteins, in breast cancer cells. (A-E) Effects of I157172 on SIRT1, acetyl-STAT3 and p-STAT3 expression. I157172 upregulated SIRT1, and decreased acetyl-STAT3 and p-STAT3 expression, in a dose-dependent manner. (F-K) Effects of I157172 on STAT3 downstream proteins. I157172 inhibited the expression of STAT3 downstream proteins, p-Akt, BCL-2, MMP-2 and MMP-9, in a dose-dependent manner. ${ }^{*} \mathrm{P}<0.05$ vs. the untreated group, ${ }^{\wedge} \mathrm{P}<0.05$ vs. the $10 \mu \mathrm{M}$ I157172 group, ${ }^{\sharp} \mathrm{P}<0.05$ vs. the $20 \mu \mathrm{M}$ I157172 group. Acetyl, acetylated; Akt, protein kinase B; BCL-2, B-cell lymphoma 2; MMP, matrix metalloproteinase; p, phosphorylated; SIRT1, sirtuin 1; STAT3, signal transducer and activator of transcription 3.

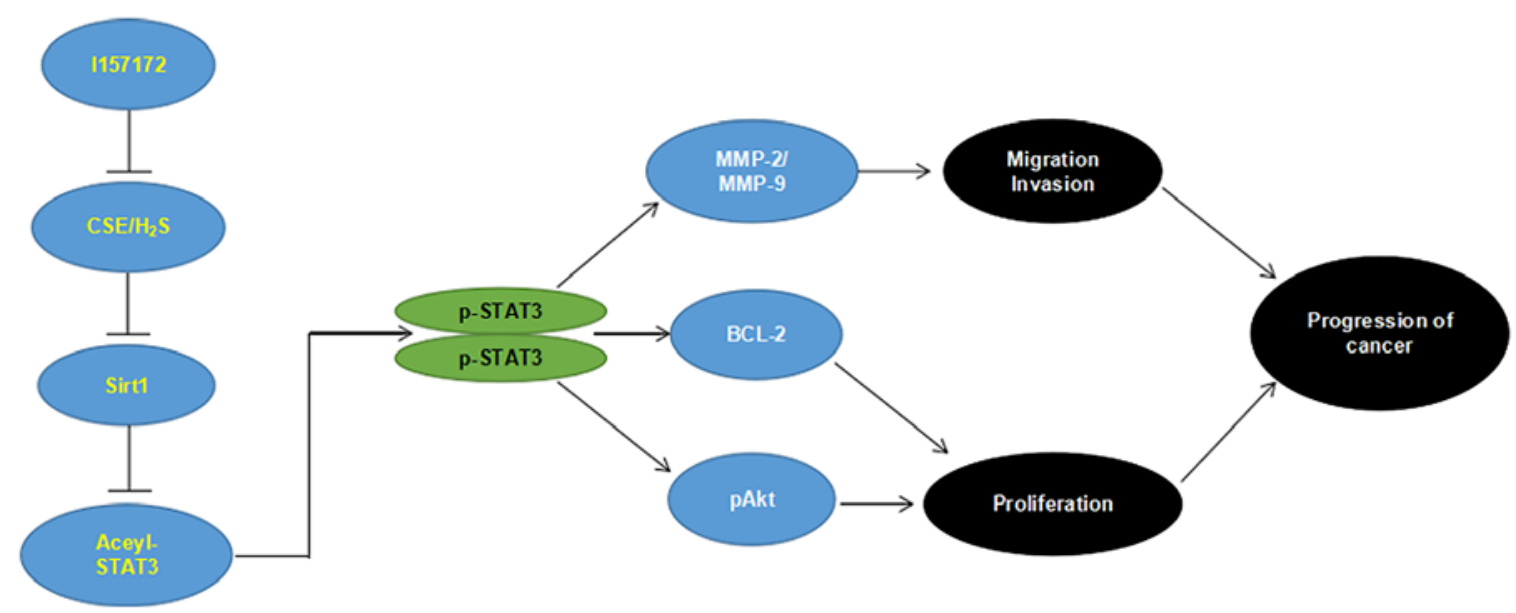

Figure 7. Schematic diagram of the mechanism underlying the inhibitory effects of I15712 on the progression of breast cancer. Blunted arrows indicate inhibition. Acetyl, acetylated; Akt, protein kinase B; BCL-2, B-cell lymphoma 2; CSE, cystathionine $\gamma$-lyase; $\mathrm{H}_{2} \mathrm{~S}$, hydrogen sulfide; MMP, matrix metalloproteinase; p, phosphorylated; SIRT1, sirtuin 1; STAT3, signal transducer and activator of transcription 3.

in the activation of STAT3 and explore the mechanism underlying the effects of the CSE inhibitor I157172 on breast cancer, the effects of 1157172 on SIRT1, acetyl-STAT3 and p-STAT3 expression were investigated. Western blotting revealed that 157172 upregulated the expression levels of SIRT1, and downregulated acetyl-STAT3 and p-STAT3 expression in a dose-dependent manner (Fig. 6A-D). Furthermore, the expression levels of STAT3 downstream proteins, p-Akt, BCL-2, MMP-2 and MMP-9, were reduced in a dose-dependent manner in MCF7 cells treated with I157172 (Fig. 6E-K). These data further confirmed the roles of the $\mathrm{CSE} / \mathrm{H}_{2} \mathrm{~S}$ system in deacetylation of STAT3 via SIRT1 in promoting breast cancer progression, and indicated that I157172 promoted SIRT1-mediated deacetylation of STAT3 in breast cancer cells and consequently inhibited the growth of breast cancer cells. 


\section{Discussion}

$\mathrm{H}_{2} \mathrm{~S}$ serves important roles in cancer cells $(8,9)$ alongside its physiological functions in normal somatic cells (27). The effects of exogenous $\mathrm{H}_{2} \mathrm{~S}$ on cancer cells differ from those of endogenous $\mathrm{H}_{2} \mathrm{~S}$. Several $\mathrm{H}_{2} \mathrm{~S}$ donors exert therapeutic effects on cancer cells (27), whereas endogenous $\mathrm{H}_{2} \mathrm{~S}$ may promote the proliferation of some cancer cells $(4,8,9)$.

CSE, which is an endogenous $\mathrm{H}_{2} \mathrm{~S}$ synthase, is a pyridoxal5 '-phosphate-dependent enzyme that catalyzes L-cysteine to yield $\mathrm{H}_{2} \mathrm{~S}(28,29)$. Our previous study focused on the biological functions of the $\mathrm{CSE} / \mathrm{H}_{2} \mathrm{~S}$ system in breast cancer and revealed that CSE expression may function as a potential tumor promoter (9); therefore, CSE may be considered a novel target for breast cancer treatment. Further study of CSE inhibitors may be of great significance for the treatment of breast cancer.

MCF7 cells retain many characteristics of differentiated mammary epithelium, and are commonly used in breast cancer research. The present study investigated the inhibitory effects of compound I157172, which is a CSE inhibitor identified using the virtual screening method, on MCF7 cells. The results revealed that the CSE inhibitor I157172 significantly inhibited the growth, proliferation and migration of MCF7 cells. Furthermore, the inhibitory effects of I157172 were significantly stronger than those of the existing CSE inhibitor PAG, and the damaging effects of 1157172 on Hs578Bst normal mammary cells were weaker than those of the positive control DOX. These findings indicated that the CSE inhibitor I157172 may possess significant anti-breast cancer activity.

STAT3 is a member of the STAT family, which has important roles in cellular transformation, proliferation, inflammation and metastasis in cancer (30). Our previous study revealed that high expression levels of CSE promote the activation of STAT3 (10). Acetylation of STAT3 is essential for STAT3 activation, whereas SIRT1 can induce deacetylation of STAT3 (16-22). Therefore, it was hypothesized that the $\mathrm{CSE} / \mathrm{H}_{2} \mathrm{~S}$ system may activate STAT3 via reducing SIRT1 levels.

To verify the aforementioned hypothesis, the expression levels of CSE and SIRT1 were detected in breast cancer tissues and cells. Notably, a negative association was determined between CSE and SIRT1 expression in breast cancer tissues and cells. In addition, SIRT1 protein levels were increased, whereas acetyl-STAT3 and p-STAT3 (Tyr705) levels were decreased in CSE knockdown MCF7 cells. Furthermore, the STAT3 downstream proteins, BCL-2, p-AKT, MMP-2 and MMP-9, were inhibited when CSE was knocked down in MCF7 breast cancer cells. Taken together, the low expression of SIRT1 might mediate the effects of the $\mathrm{CSE} / \mathrm{H}_{2} \mathrm{~S}$ system on STAT3 activation, consequently promoting the progression of breast cancer.

To further confirm the aforementioned hypothesis, the effects of I157172 were investigated on SIRT1/acetyl-STAT3. The results revealed that 157172 induced upregulation of SIRT1, and downregulation of acetyl-STAT3 and p-STAT3 (Tyr705), as well as inhibition of STAT3 downstream proteins.

In conclusion, to the best of our knowledge, the present study is the first to demonstrate that reduced expression of SIRT1 may mediate the effects of the $\mathrm{CSE} / \mathrm{H}_{2} \mathrm{~S}$ system on STAT3 activation, consequently promoting breast cancer development and progression. In addition, the novel CSE inhibitor I157172 possessed anti-breast cancer activity via the SIRT1/acetyl-STAT3 signaling pathway (Fig. 7). The present study provided novel insights into the function and mechanism of the $\mathrm{CSE} / \mathrm{H}_{2} \mathrm{~S}$ system in cancer cells, and indicated that $\mathrm{CSE} / \mathrm{H}_{2} \mathrm{~S}$ system inhibitors may be potential candidates for the treatment of breast cancer. In future studies, we aim to further explore the anticancer effects and mechanism of I157172 in vivo.

\section{Acknowledgements}

Not applicable.

\section{Funding}

The present study was financially supported by grants from the Key Science and Technology Fund of Henan Province in China (grant no.162300410035) and the Henan Province University Science and Technology Innovation Team (grant no. 16IRTSTHN019).

\section{Availability of data and materials}

All data generated or analyzed during this study are included in this published article.

\section{Authors' contributions}

TW and XS conceived and designed the experiments. LW, HS and XiaoyuZ performed the experiments. LW, HS, XiaoyuZ, XiuliZ, YL and WK analyzed the data and made the figures. LW wrote and proofread the paper. TW and XS revised the manuscript. All authors read and approved the manuscript and agree to be accountable for all aspects of the research in ensuring that the accuracy or integrity of any part of the work are appropriately investigated and resolved.

\section{Ethics approval and consent to participate}

This study was approved by the Ethics Committee of Medical School, Henan University. Patients provided written informed consent.

\section{Patient consent for publication}

Patient consent for publication was received.

\section{Competing interests}

The authors declare that they have no competing interests.

\section{References}

1. Shi XJ, Au WW, Wu KS, Chen LX and Lin K: Mortality characteristics and prediction of female breast cancer in China from 1991 to 2011. Asian Pac J Cancer Prev 15: 2785-2791, 2014.

2. Wang R: Hydrogen sulfide: The third gasotransmitter in biology and medicine. Antioxid Redox Signal 12: 1061-1064, 2010.

3. Coletta C, Papapetropoulos A, Erdelyi K, Olah G, Módis K, Panopoulos P, Asimakopoulou A, Gerö D, Sharina I, Martin E, et al: Hydrogen sulfide and nitric oxide are mutually dependent in the regulation of angiogenesis and endothelium-dependent vasorelaxation. Proc Natl Acad Sci USA 109: 9161-9166, 2012. 
4. Szabo C, Coletta C, Chao C, Módis K, Szczesny B, Papapetropoulos A and Hellmich MR: Tumor-derived hydrogen sulfide, produced by cystathionine- $\beta$-synthase, stimulates bioenergetics, cell proliferation, and angiogenesis in colon cancer Proc Natl Acad Sci USA 110: 12474-12479, 2013.

5. Kimura Y, Goto Y and Kimura H: Hydrogen sulfide increases glutathione production and suppresses oxidative stress in mitochondria. Antioxid Redox Signal 12: 1-13, 2010.

6. Sheng J, Shim W, Wei H, Lim SY, Liew R, Lim TS, Ong BH, Chua YL and Wong P: Hydrogen sulphide suppresses human atrial fibroblast proliferation and transformation to myofibroblasts. J Cell Mol Med 17: 1345-1354, 2013.

7. Popov D: An outlook on vascular hydrogen sulphide effects, signalling, and therapeutic potential. Arch Physiol Biochem 119: 189-194, 2013.

8. Cai WJ, Wang MJ, Ju LH, Wang C and Zhu YC: Hydrogen sulfide induces human colon cancer cell proliferation: Role of Akt, ERK and p21. Cell Biol Int 34: 565-572, 2010.

9. Yin P, Zhao C, Li Z, Mei C, Yao W, Liu Y, Li N, Qi J, Wang L, Shi Y, et al: $\mathrm{Sp} 1$ is involved in regulation of cystathionine $\gamma$-lyase gene expression and biological function by PI3K/Akt pathway in human hepatocellular carcinoma cell lines. Cell Signal 24 1229-1240, 2012.

10. You J, Shi X, Liang H, Ye J, Wang L, Han H, Fang H, Kang W and Wang T: Cystathionine- $\gamma$-lyase promotes process of breast cancer in association with STAT3 signaling pathway. Oncotarget 8: 65677-65686, 2017.

11. Lin L, Hutzen B, Zuo M, Ball S, Deangelis S, Foust E, Pandit B Ihnat MA, Shenoy SS, Kulp S, et al: Novel STAT3 phosphorylation inhibitors exhibit potent growth-suppressive activity in pancreatic and breast cancer cells. Cancer Res 70: 2445-2454, 2010.

12. Hutzen B, Friedman L, Sobo M, Lin L, Cen L, De Angelis S, Yamakoshi H, Shibata H, Iwabuchi Y and Lin J: Curcumin analogue GO-Y030 inhibits STAT3 activity and cell growth in breast and pancreatic carcinomas. Int J Oncol 35: 867-872, 2009.

13. Groner B, Lucks P and Borghouts C: The function of Stat 3 in tumor cells and their microenvironment. Semin Cell Dev Biol 19: 341-350, 2008

14. Yu H, Pardoll D and Jove R: STATs in cancer inflammation and immunity: A leading role for STAT3. Nat Rev Cancer 9: 798-809, 2009.

15. Liu A, Liu Y, Xu Z, Yu W, Wang H, Li C and Lin J: Novel small molecule, XZH-5, inhibits constitutive and interleukin-6-induced STAT3 phosphorylation in human rhabdomyosarcoma cells Cancer Sci 102: 1381-1387, 2011.

16. Yuan ZL, Guan YJ, Chatterjee D and Chin YE: Stat3 dimerization regulated by reversible acetylation of a single lysine residue. Science 307: 269-273, 2005
17. Wang R, Cherukuri $\mathrm{P}$ and Luo J: Activation of Stat 3 sequencespecific DNA binding and transcription by $\mathrm{p} 300 / \mathrm{CREB}-$ binding protein-mediated acetylation. J Biol Chem 280: 11528-11534, 2005.

18. Wang Y, Zhou C, Gao H, Li C, Li D, Liu P, Huang M, Shen X and Liu L: Therapeutic effect of Cryptotanshinone on experimental rheumatoid arthritis through downregulating p300 mediatedSTAT3 acetylation. Biochem Pharmacol 138: 119-129, 2017.

19. Dasgupta M, Unal H, Willard B, Yang J, Karnik SS and Stark GR: Critical role for lysine 685 in gene expression mediated by transcription factor unphosphorylated STAT3. J Biol Chem 289: 30763-30771, 2014.

20. Zhuang S: Regulation of STAT signaling by acetylation. Cell Signal 25: 1924-1931, 2013.

21. Sestito R, Madonna S, Scarponi C, Cianfarani F, Failla CM, Cavani A, Girolomoni G and Albanesi C: STAT3-dependent effects of IL-22 in human keratinocytes are counterregulated by sirtuin 1 through a direct inhibition of STAT3 acetylation. FASEB J 25: 916-927, 2011

22. Nie Y, Erion DM, Yuan Z, Dietrich M, Shulman GI, Horvath TL and Gao Q: STAT3 inhibition of gluconeogenesis is downregulated by SirT1. Nat Cell Biol 11: 492-500, 2009.

23. Chung YR, Kim H, Park SY, Park IA, Jang JJ, Choe JY, Jung YY, Im SA, Moon HG, Lee KH, et al: Distinctive role of SIRT1 expression on tumor invasion and metastasis in breast cancer by molecular subtype. Hum Pathol 46: 1027-1035, 2015.

24. Xu Y, Qin Q, Chen R, Wei C and Mo Q: SIRT1 promotes proliferation, migration, and invasion of breast cancer cell line MCF-7 by upregulating DNA polymerase delta1 (POLD1). Biochem Biophys Res Commun 502: 351-357, 2018.

25. Jin X, Wei Y, Xu F, Zhao M, Dai K, Shen R, Yang S and Zhang N: SIRT1 promotes formation of breast cancer through modulating Akt activity. J Cancer 9: 2012-2023, 2018.

26. Rifaï K1: Judes G, Idrissou M, Daures M, Bignon YJ, PenaultLlorca F and Bernard-Gallon D: Dual SIRT1 expression patterns strongly suggests its bivalent role in human breast cancer. Oncotarget 8: 110922-110930, 2017.

27. Lee ZW and Deng LW: Role of H2S donors in cancer biology. Handb Exp Pharmacol 230: 243-265, 2015.

28. Kimura H: Hydrogen sulfide: from brain to gut. Antioxid Redox Signal 12: 1111-1123, 2010.

29. Wang R: Hydrogen sulfide: the third gasotransmitter in biology and medicine. Antioxid Redox Signal 12: 1061-1064, 2010.

30. Aggarwal BB, Kunnumakkara AB, Harikumar KB, Gupta SR, Tharakan ST, Koca C, Dey S and Sung B: Signal transducer and activator of transcription-3, inflammation, and cancer: How intimate is the relationship? Ann NY Acad Sci 1171: 59-76, 2009. 